Bulgarian Journal of Veterinary Medicine, 2015, 18, № 4, 367-372

ISSN 1311-1477; DOI: 10.15547/bjvm.871

Original article

\title{
INFLUENCE OF SOME FACTORS ON THE INCIDENCE OF PYOMETRA IN THE BITCH
}

\author{
A. L. ANTONOV, A. S. ATANASOV, I. R. FASULKOV, P. I. GEORGIEV, \\ S. A. YOTOV, M. P. KARADAEV \& N. Y. VASILEV \\ Department of Obstetrics, Reproduction and Reproductive Disorders, Faculty \\ of Veterinary Medicine, Trakia University, 6000, Stara Zagora, Bulgaria
}

\section{Summary}

Antonov, A. L., A. S. Atanasov, I. R. Fasulkov, P. I. Georgiev, S. A. Yotov, M. P. Karadaev \& N. Y. Vasilev, 2015. Influence of some factors on the incidence of pyometra in the bitch. Bulg. J. Vet. Med., 18, No 4, 367-372.

The aim of the present study was to determine the influence of breed, age, season, mating, pregnancy, progestin contraceptive treatment and the onset time of the disease after the last heat on the incidence and epidemiology of canine pyometra in Bulgaria. The investigation included 217 bitches suffering from pyometra. We found that the disorder was most often observed in 7-year-old, mixed breed bitches, most frequently in September and 4 weeks after the heat.

Key words: age, bitch, breed, incidence, pyometra, season

\section{INTRODUCTION}

Pyometra is characterised by uterine bacterial infection with pus accumulating in the uterus and systemic illness (Borresen, 1975). It is the most frequent disease of the reproductive tract in bitches and of great practical importance (Kempisty et al., 2013). Affected animals are mainly older, over eight years of age (Egenvall et al., 2001). Usually pyometra occurs during the luteal phase following estrus (Blendinger et al., 1997), although anestrдus bitches also can be diagnosed with pyometra (approximately one third of the total cases) (Noakes et al., 2001).

Canine pyometra should be included in the differential diagnosis for any intact bitch, regardless of the presenting signs (Smith, 2006). Bitches with pyometra may be either with or without vaginal discharge (open-cervix or closed-cervix pyometra) (Verstegen et al., 2008).

The disease is common in countries where neutering healthy dogs is not generally practiced (Egenvall et al., 2001; Ortega-Pacheco et al., 2012). Despite modern treatment routines, the mortality rate due to pyometra is still approximately 3 4\% (Egenvall et al., 2001).

The aim of the present study was to determine the influence of breed, age, season, mating, pregnancy, progestine contraceptive treatment and the onset time of the 
disease after the last heat on the incidence of pyometra in bitches in Bulgaria.

\section{MATERIALS AND METHODS}

The investigation included 217 bitches from 48 breeds, aged 1-17 years, presented at the Small Animal Clinic of the Faculty of Veterinary Medicine, Trakia University, Stara Zagora, Bulgaria. Data concerning breed, age, mating, pregnancy, progestine contraceptive treatment and the onset time of the disease after the last heat were collected from the patient registry between 2006-2014.

All the bitches were brought to the clinic because of general malaise and/or vulvar discharge. Some of the animals were treated medically and others - surgically by performing ovariohysterectomy.

The results of our trial were expressed as means $\pm \mathrm{SD}$ and were analysed by nonparametric analysis for comparison of proportions based on Student's t-criterion (StatSoft 1984-2000 Inc. Copyright 19901995, Microsoft Corp.). $\mathrm{P} \leq 0.05$ was considered significant.

\section{RESULTS}

The age of animals varied from 1 to 17 years (mean $7.55 \pm 3.45$ years). Sevenyear-old bitches made up to $11.98 \%$ of all cases (Fig. 1). The onset time of pyometra was most frequently 4 weeks after the last heat $(33.18 \%$ of all cases). When the animals were brought to the clinic, $87.1 \%$ of them were in diestrus (within 2 months after the heat) and the other $12.9 \%$ were in the anestrus stage $(\mathrm{P}<0.001)$.

Analysing the morbidity of pyometra we found that mixed breed bitches were $14.75 \%$, Miniature Pinschers $-8.29 \%$ and Rottweilers $-7.37 \%$ of all cases (Table 1). Small breeds such as Bolognese, Miniature Pincher and Pekingese developed pyometra later in their life $(12.57 \pm 2.44,8.44 \pm 4.12$ and $8.22 \pm 3.80$ years respectively) compared to large breed dogs such as Caucasian Shepherd and Bulgarian Shepherd (6.00 \pm 3.24 and $6.25 \pm 1.67$ years respectively). In our investigation Siberian Husky bitches were the first to develop the disease at $5.67 \pm 3.98$ years of age.

Seasonal patterns of pyometra showed that most frequently the disease occurred

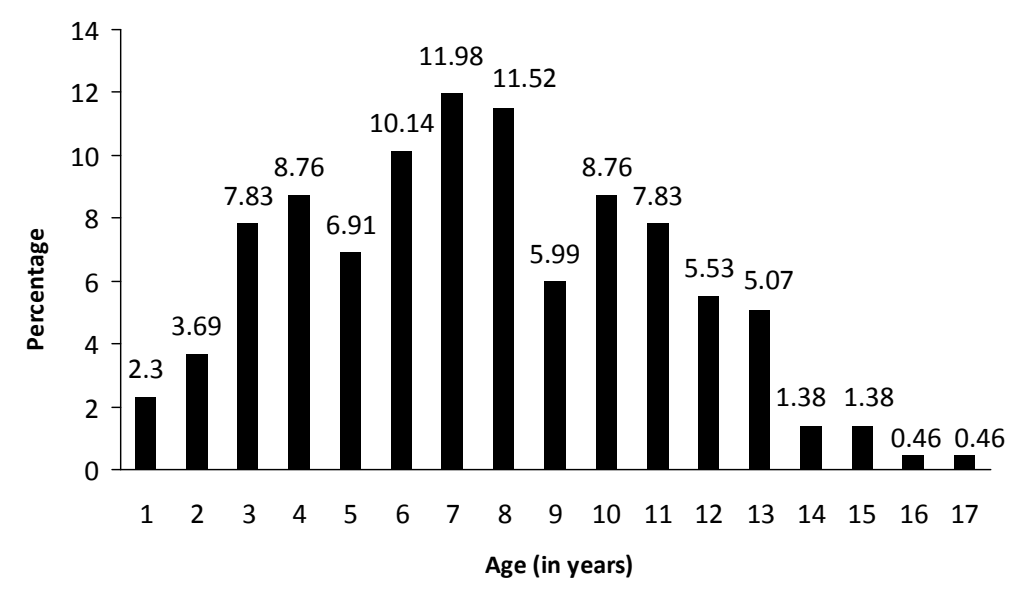

Fig. 1. Morbidity of pyometra depending on the age of the bitches. 
A. L. Antonov, A. S. Atanasov, I. Fasulkov, P. I. Georgiev, S. A. Yotov, M. P. Karadaev \& N. Y. Vasilev

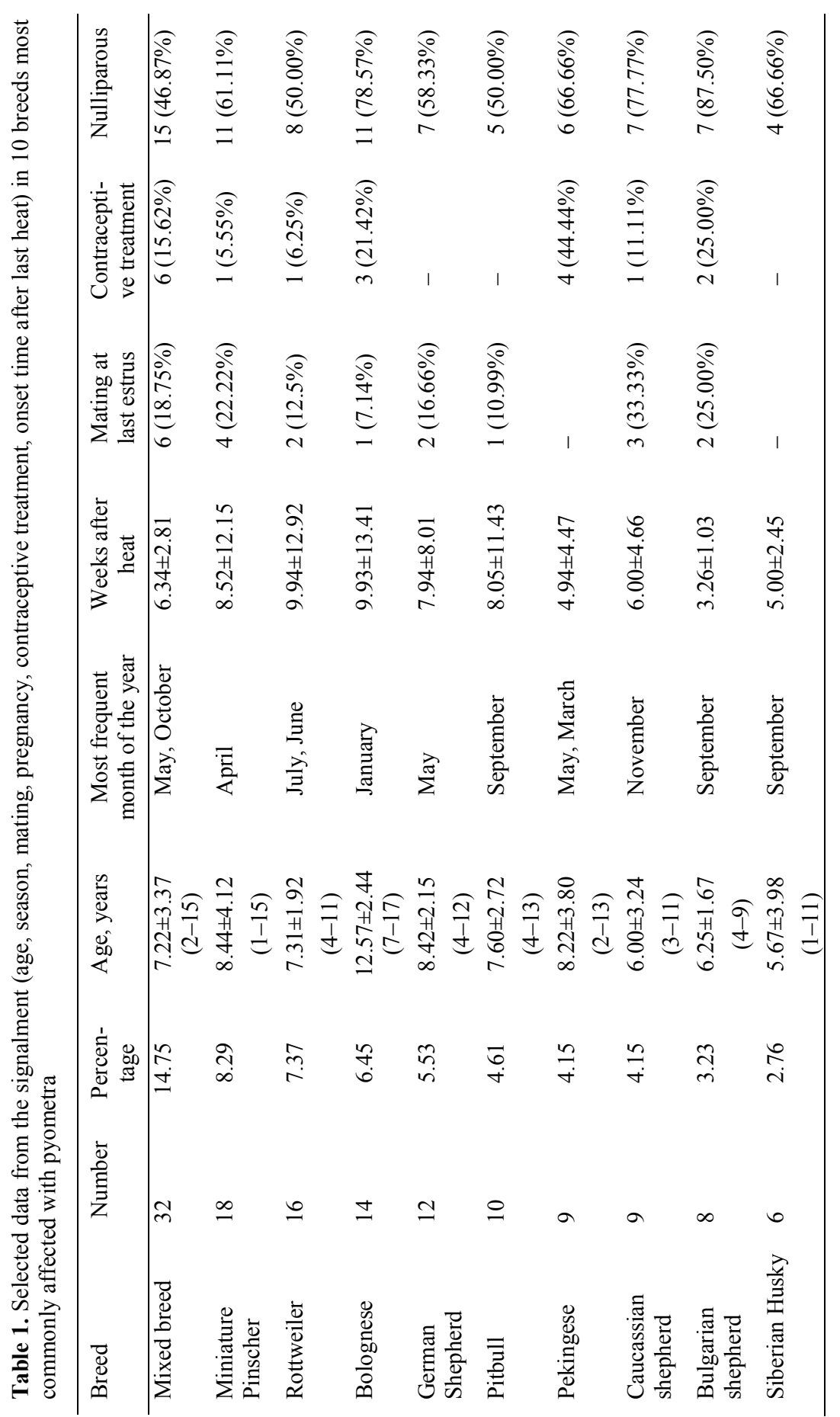

BJVM, 18, No 4 


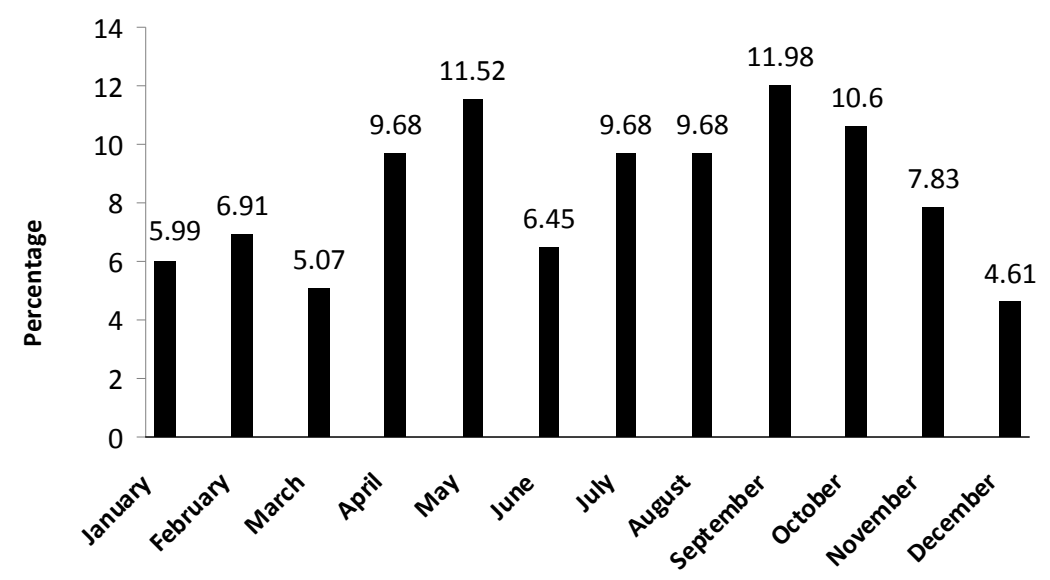

Fig. 2. Influence of season on pyometra morbidity in bitches.

in September (11.98\%), May (11.52\%) and October $(10.6 \%)$. The lowest number of cases was observed in the winter (Fig. 2).

During the last estrus $16.59 \%$ of the animals were mated, while the other $83.41 \%$ had no sexual contact $(\mathrm{P}<0.001)$. Only $10.6 \%$ of bitches had had a previous progesterone contraceptive treatment and the other $89.4 \%$ had not ever been treated with any contraceptives $(\mathrm{P}<0.001)$. Of all dogs, $62.21 \%$ were nulliparous and $37.79 \%$ were multiparous $(\mathrm{P}<0.001)$.

\section{DISCUSSION}

Our investigation examined some specific characteristics of the epidemiology of canine pyometra in Bulgaria. This disorder of the uterus in nonpregnant, sexually mature bitches is usually diagnosed from 4 weeks to 4 months after the end of estrus (Smith, 2006). We also observed it more frequently in diestrous bitches, when progesterone secretion resulted in endometrial proliferation and uterine glandular secretion, accompanied with suppression of immune responses, decreased myo- metrial contraction and closure of the cervix (Borresen, 1975; Parvanov \& Stefanova-Gerganova, 1998; Smith, 2006). Although the association between pyometra and diestrus has been well established, the precise mechanism is still not clear (Borresen, 1975). We also registered the disease in anestrous bitches. Leukocyte inhibition in the progesterone-primed uterus often supports bacterial growth. All these effects are cumulative and each estrous cycle is exacerbating this uterine pathology (Sugiura et al., 2004).

According to Laurusevicius (2009), pyometra is most often observed in eight years old bitches, a month after the heat, in July and August and the breed most frequently affected is Rottweiler. Our results confirm that canine pyometra is more often observed in older and most frequently in 7-8 years old bitches (Chastain et al., 1999; Egenvall et al., 2001), but as could be seen from Fig. 1, there was also a significantly high percentage of morbidity in 3- and 4-year-old animals. Because of different age patterns of the risk of developing pyometra, the optimal age for elective spaying differs among breeds. 
There is an increased risk for the disease in seventeen breeds, whereas the Wire-Haired Dachshund and mixed breed were at a lower risk of developing it (Egenvall et al., 2001). In contrast to previous studies (Niskanen \& Thrusfield, 1998; Laurusevicius, 2009), we diagnosed most frequently pyometra in mixed breed bitches (14.75\%) and our results confirmed the findings that Rottweilers were one of the most affected breeds (Niskanen \& Thrusfield, 1998; Hagman, 2004; Smith, 2006; Laurusevicius, 2009). These breeds may have a higher genetic predisposition for developing pyometra than other breeds so the possibilility of instituting breeding programmes for disease control might be considered.

Analysis of seasonal occurrence of pyometra showed that the biggest number of cases was registered in September $(11.98 \%)$ and May $(11.52 \%)$, i.e. in the autumn and spring, while Laurusevicius (2009) reported highest morbidity of pyometra in the summer. In our opinion, this was due to the local geographical factors.

According to Niskanen \& Thrusfield (1998), no significant risk-enhancing effect of progestin treatment and mating for developing pyometra was detected. Our results confirmed this so we conclude that the possible risk was probably low. We also found that nulliparous bitches were at a moderately higher risk of developing pyometra (almost $2: 1$ ), as already observed (Noakes et al., 2001; Verstegen et al., 2008).

\section{REFERENCES}

Blendinger, K., H. Bostedt \& B. Hoffmann, 1997. Hormonal effects of the use of an antiprogestin in the bitches with pyometra. Journal of Reproduction and Fertility Suppl, 51, 317-325.
Borresen, B., 1975. Pyometra in the dog: a pathophysiological investigation. I. The pyometra syndrome, a review. Nordisk Veterinaermedicin, 27, 508-517.

Chastain, C., D. Panciera \& C. Waters, 1999. Association between age, parity, hormonal therapy and breed, and pyometra in Finnish dogs. Small Animal Endocrinology, 9, 8 .

Egenvall, A., R. Hagman, B. Bonnett, A. Hedhammar, P. Olson \& A. Lagerstedt, 2001. Breed risk of pyometra in insured dogs in Sweden. Journal of Veterinary Internal Medicine, 15, 530-538.

Hagman, R., 2004. New aspects of canine pyometra: studies on epidemiology and pathogenesis. Doctoral thesis, pp. 25-28.

Kempisty, B., D. Bucowska, M. Wozna, H. Piotrowska, M. Jacowska, A. Zuraw, S. Ciesiolka, P. Antosik, H. Maryniak, E. Ociepa, Sz. Porowski, K. Brussow, J. Jaskowski \& M. Nowicki, 2013. Endometritis and pyometra in bitches: A review. Veterinarni Medicina, 58, 289-297.

Laurusevicius, S., 2009. Reproductive parameters of bitches and examination of vaginal microflora during different stages of reproductive cycle. Summary of doctoral dissertation, Lithuanian Veterinary Academy, Kaunas, 15-18.

Niskanen, M. \& M. Thrusfield, 1998. Association between age, parity, hormonal therapy and breed, and pyometra in Finnish dogs. The Veterinary Record, 43, 493-498.

Noakes, D., G. Dhaliwal \& G. England, 2001. Cystic endometrial hyperplasia/pyometra in the dog: A review. Journal of Reproduction and Fertility Suppl, 57, 395-406.

Ortega-Pacheco, A., E. Gutierez-Blanco \& M. Jimenez-Coello, 2012. Common lesions in the female reproductive tract of dogs and cats. Veterinary Clinics of North America: Small Animal Practice, 42, 547-559.

Parvanov, P. \& E. Stefanova-Gerganova, 1998. Use of hormonal drugs for control of reproduction and medication of gynaecological diseases in bitches. Veterinary Medicine (Sofia), 2, 154-157 (BG). 
Sugiura, K., M. Nishikawa, K. Ishiguro, T. Tajima, M. Inaba \& R. Torrii, 2004. Effect of ovarian ovarian hormones on periodical changes in immune resistance associated with estrous cycle in the beagle bitch. Immunobiology, 209, 619-627.

Smith, F., 2006. Canine pyometra. Theriogenology, 66, 610-612.

Verstegen, J., G, Dhaliwal \& K. VerstegenOnclin, 2008. Mucometra, cystic endometrial hyperplasia, and pyometra in the bitch: Advances in treatment and assessment of future reproductive success. Theriogenology, 70, 364-374.
Paper received 31.10.2014; accepted for publication 22.01.2015

\section{Correspondence:}

Anton Antonov, DVM, PhD

Department of Obstetrics, Reproduction and Reproductive Disorders,

Faculty of Veterinary Medicine,

Trakia University,

6000 Stara Zagora, Bulgaria,

e-mail: anton.antonov@abv.bg 